\title{
Reducing the Edge Chipping for Capillary End Face Grinding and Polishing
}

\author{
J. Hošek ${ }^{1,2}$ and K. Studenovský ${ }^{1}$ \\ ${ }^{1}$ Czech Technical University in Prague, Faculty of Mechanical Engineering, Technická 4, 16607 Praha 6, Czech Republic \\ ${ }^{2}$ Institute of Thermomechanics AS CR v.v.i., Czech Academy of Sciences, Dolejškova 5, 18200 Praha 8, Czech Republic
}

\begin{abstract}
This paper presents results of glass capillary end face grinding and polishing by approach that reduces the edge chipping. Brittle materials have natural tendency for edge chipping what leads to beveling the sharp edges. Not beveled sharp edges on glass capillary are important for special applications like surface tension measurement of small liquid samples. We use common grinding and polishing process for capillary end face machining modified with gradual decreasing of grinding load based on the relation of the critical chipping load. Achieved surface roughness is measured using atomic force microscopy (AFM). Capillary inner edge quality is checked both with optical microscopes and electron microscope too. We achieved a non-chipped capillary inner edge with radius down to $100 \mathrm{~nm}$.
\end{abstract}

\section{Introduction}

This paper presents labor technique and experimental conditions that we use within grinding and polishing to achieve sharp inner edge without chipping of glass capillary. Sharp inner edge of capillary is one of the necessary conditions for successful liquid surface tension measurement using Ferguson method [1]. Although this experimental method is not a standard method for liquid surface tension measurement, it is the only method that can be used for surface tension measurement of small amount of liquid at supercritical state [2].

The Ferguson surface tension measurement method is based on measurement of pressure difference across a small (less than $1 \mathrm{~mm}^{3}$ ) liquid sample placed in a small diameter capillary, under condition of flat sample meniscus at the capillary tip. Details of prepared experiment can be found in [3].

Sample meniscus flatness is very strongly affected by any defects on the inner capillary edge as non-flatness of capillary tip, edge chipping and dust or impurities contamination, what can be seen in the figure 1. To overcome mentioned problems an optimum technology of capillary sharp inner edge preparation and cleaning had to be found.

A standard technique of capillary splitting is its cleaving using some of standard capillary cleaving tools. This technique is based on introduction of small welldefined mechanical stress to the capillary surface layer and then its propagation across the capillary profile. When cleaving occurs, mechanical stress propagates as a shock wave, where the wave front forms small lines or circles of variable height in the cut as a product of typical conchoidal fracture. There can appear another cut defects on capillary tip too. This technique gives good shape and surface quality applied to fibers. But the quality of cleaved capillary inner edge is not always sharp and smooth sufficiently, that affects the observed shape of liquid sample planar meniscus. We have to finish cleaved capillary tip to fulfill our needs.

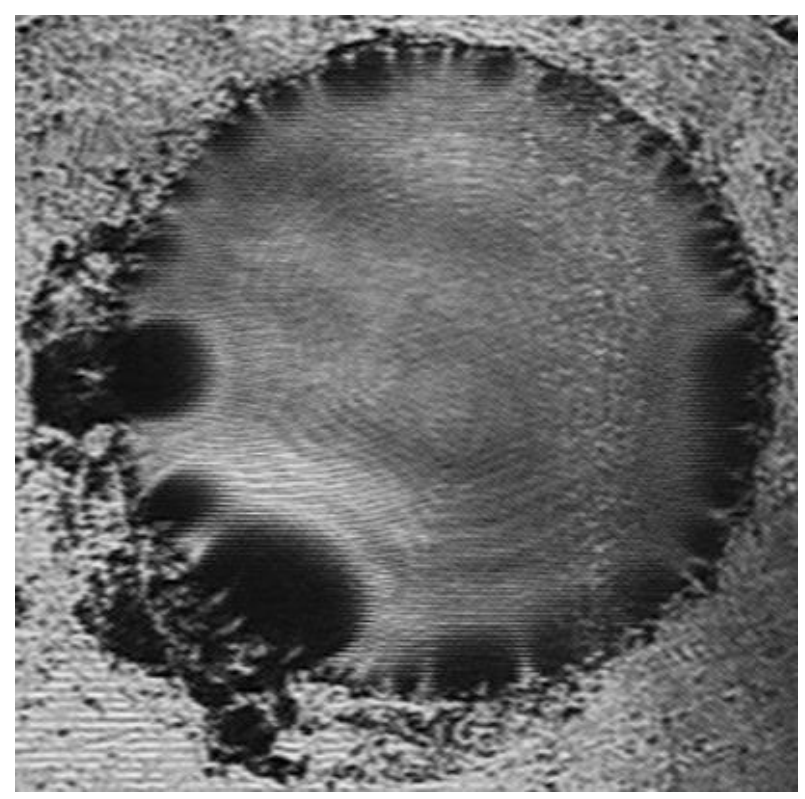

Fig. 1. An example of influence of the inner edge capillary defects on the meniscus shape

This is an Open Access article distributed under the terms of the Creative Commons Attribution License 2.0, which permits unrestricted use, distribution, and reproduction in any medium, provided the original work is properly cited. 
Problems of capillary finishing using grinding or polishing are very weakly referred. Usually capillary inner wall finishing is studied only [4-6]. More references can be find on fiber faces production [7-9], where the machining area has similar dimensions. The problem of optimal machining parameters set was studied with respect to optical surface quality achieved at minimal working time [10-13] especially. But the main technical problem of small glass area machining consists of material edge chipping [13]. This problem was well known for old gem cutters, who say, any brittle materials should not be ground at angles $90^{\circ}$ or less. Recent paper confirms this old experimental experience and it introduces a simple and universal relation of edge chipping [14]. This fact is traditionally solved with beveled edges of optics, what is not acceptable in our case.

Next in the text the grinding machine used for sharp inner edge glass capillary finishing is presented. The grinding and polishing process is then described and working conditions are presented. Finally the problem of the capillary inner edge check is also discussed.

\section{Experimental set-up}

As a good machine for capillary edge machining we decided to use a small grinding machine originally designed for grinding of diamond crystals intended for single point diamond machining. The reasons were the similar dimensions of capillary tip as grinded diamonds and sharp edge enough achieved in the case of diamond grinding. This machine had to be slightly modified, where the original work piece holder head allowing two perpendicular working angles set was replaced with the career plate mount slightly above grinding plate and enables to hold two work pieces. We use this modification on base of our previous experience [15].

Used grinding machine is shown in the figure 2 .

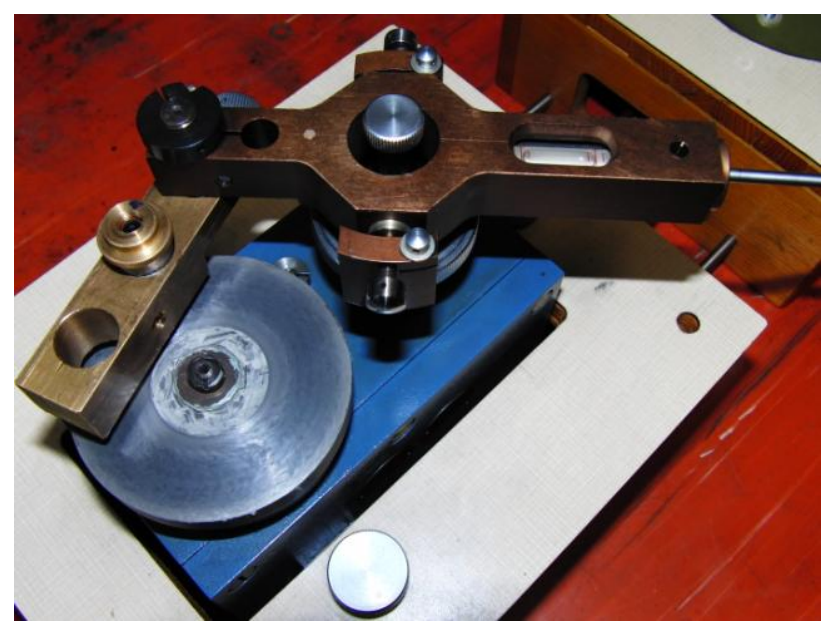

Fig. 2. The grinding machine.

Machine consists of cast iron grinding plate of $80 \mathrm{~mm}$ diameter driven by external electric motor. Cleaved fused silica capillary with diameters $0.98 / 0.32 \mathrm{~mm}$ and length $35 \mathrm{~mm}$ is clamped in $1.1 \mathrm{~mm}$ collet inside a holder head. The work piece holder head is slide into the career plate hole mounted to the swinging lever. Capillary load is set in single steps with weight assembly or continuously by spring and measured with digital force meter. Capillary perpendicular position is given with geometrical tolerance of holder head of diameter $16.1 \mathrm{~mm}$ and it was better than $6^{\prime}$. Grinding plate speed can vary in range 60 $1200 \mathrm{rpm}$ with use of frequency changer. The swinging motion of the workpiece on the grinding plate takes range of $58-90 \%$ of grinding plate diameter. Velocity of this movement is proportional to the grinding plate speed with ratio $1: 240$. This movement causes the capillary grinding speed variation in the range of $0.85-1.15$ of grinding speed $v_{0}$ at $56 \mathrm{~mm}$ diameter. The in-feed rate set by the capillary holder head load was in the range of 10-220 $\mathrm{mN} / \mathrm{mm}^{2}$.

\section{Experimental conditions}

We performed a series of experimental tests of capillary face machining process with the goal to achieve a sharp capillary inner edge. Machining process consists of classical optical grinding involved grinding using $3 / 2$ and $1 / 0 \mu \mathrm{m}$ diamond grit and finishing using $\mathrm{Fe}_{2} \mathrm{O}_{3}$ dispersed on polishing pad.

Defects observed on the capillary surface during the grinding originate in two grounds. The first one is caused by brittle grinding mode; the second one originates in inner stress in the capillary induced within its manufacture or dividing process. Both effects are enhanced with the increase of in-feed rate or by mechanical vibrations of the capillary during its grinding. The essential condition necessary for the sharp capillary edge achieving is to ensure ductile regime $[16,17]$ of surface removal. This condition, however, is not sufficient condition for satisfaction sharp edge manufacturing, because small defects appear on the machining edge under ductile regime too as it is seen in the figure 3 .

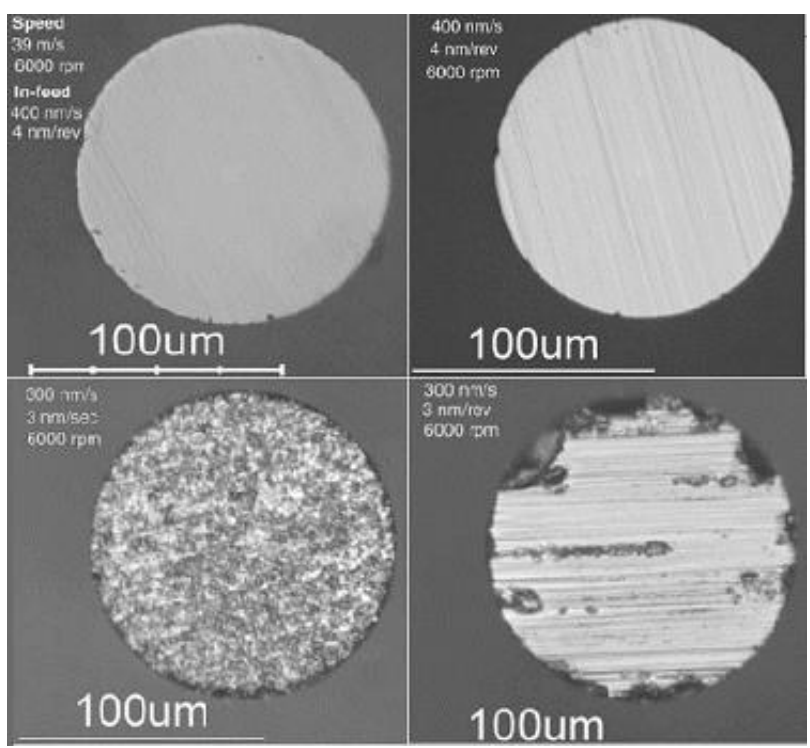

Fig. 3. The optical fiber tip edge chipping using diamond grit

$0.5 \mu \mathrm{m}, 1 \mu \mathrm{m}, 3 \mu \mathrm{m}$ and $5 \mu \mathrm{m}$ under similar machining conditions $6000 \mathrm{rpm}$ and in-feed rate $400(300) \mathrm{nm} / \mathrm{s}$ [13]

It is a consequence that each acting grit can be assumed to be a cutting edge with temporal statistically 
variable removal rate close to the average value. The ductile regime of surface grinding is limited with critical depth of grit penetration to the surface, which is proportional to the loading force. But the critical load force $P_{F}$ causing edge chipping dramatically changes close to the edge [14] according equation (1):

$$
P_{F}=\beta K_{C} d^{\frac{3}{2}}
$$

where $\beta$ is the constant independent of the material, $K_{C}$ is the toughness of the glass and $d$ is the distance of load force from the edge. Because of this exponential dependence of critical load, the little variation of the grit load close to the edge leads to intensive edge chipping otherwise the overall surface quality maintains well. We decided to minimize this negative effect on the glass capillary edge quality.

Our approach to reach sharp capillary inner edge starts with capillary cleaving. We cut the capillary surface with a diamond capillary cleaving tools and then broke the capillary placed inside the collet. The next approach depends on the kind of defects present in the cleaved capillary face.
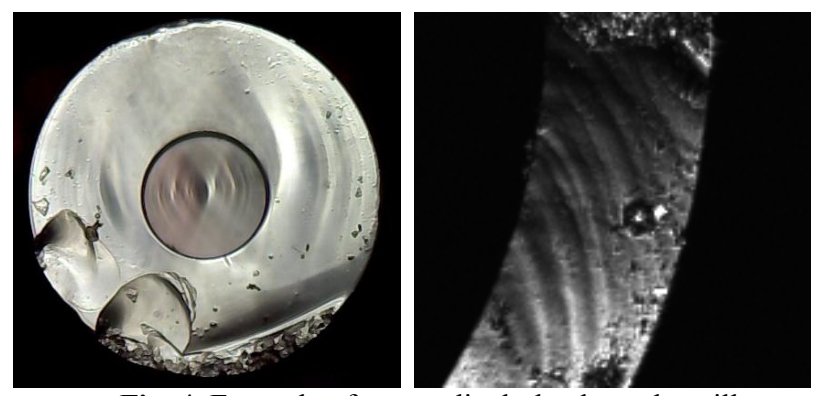

Fig. 4. Example of perpendicularly cleaved capillary (left) and obliquely cleave with conchoidal fracture lines causing surface roughness deviations up to $15 \mu \mathrm{m}$ (right)

There are two basic criterions affecting next capillary face machining process - the tilt angle of cut to the capillary axis and the magnitude of deviation from cut planarity. If the face is perpendicular to the capillary axis (checked with profile projector) and defects on capillary inner edge have dimensions under $5 \mu \mathrm{m}$ the capillary finishing process consist of its polishing only. In other cases the grinding process has to be introduced.

We usually use $1 / 0 \mu \mathrm{m}$ grit for capillary fine grinding. If large volume of material has to be removed we use $3 / 2 \mu \mathrm{m}$ grit. Then we ground the capillary tip to the flat surface using $1 / 0 \mu \mathrm{m}$ grit what takes $2-5$ minutes of grinding. After this stage few small defects up to $5 \mu \mathrm{m}$ are usually observed only. It gives us information about the critical load value, which can be expected during the next machining. To obliterate these defects we gradually decrease load during next grinding. The optimum decrease of the load seems to be according function derived from equation (1):

$P(t)=P_{F}(H-h(t))^{\frac{3}{2}}$ where $P_{F}$ is the original load causes defects up to depth $H$ under the capillary tip surface and $h(t)$ is the actual grinding depth. This relation originates in conception that all next defects caused by the same random load variation of individual grits will be always smaller then defects caused within the first part of grinding. This idea is schematically shown in the figure 5 .

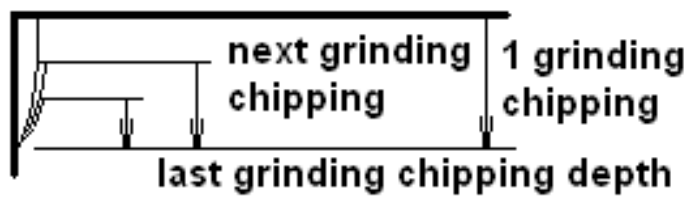

Fig. 5. The idea gradual chipping decrease of the edge

We presumed a linear function of removal rate for determining next grinding steps according equation 3 :

$h t=k{ }_{0}^{T} P t d t$,

where $k$ is the coefficient derived from the first grinding stage $k=h /\left(P_{F} T_{0}\right)$, where $h$ is the total depth of grinding, $P_{F}$ is the original load value and $T_{0}$ is the total machining time. The solution of equations (2) and (3) is a power function, but we decided to simplify it with use of maximally three single steps:

$$
\begin{array}{lll}
\text { 0) } & \mathrm{P}_{0}=\mathrm{P}_{\mathrm{F}} & \mathrm{T}=\mathrm{T}_{0} \\
\text { 1) } & \mathrm{P}_{1}=\mathrm{P}_{\mathrm{F}} / 4 & \mathrm{~T}=4 * \mathrm{~T}_{0} \\
\text { 2) } & \mathrm{P}_{2}=\mathrm{P}_{\mathrm{F}} / 16 & \mathrm{~T}=16 * \mathrm{~T}_{0} \\
\text { 3) } & \mathrm{P}_{3}=\mathrm{P}_{\mathrm{F}} / 64 & \mathrm{~T}=64 * \mathrm{~T}_{0}
\end{array}
$$

This approach could facilitate to make sharp edge on the brittle material by reducing edge defects to $12.5 \%$ of its original dimension. Next steps would too extend grinding process duration with low influence to eliminating of remaining defects. Defects of such dimensions can be successfully removed by polishing process.

\section{Results}

Firstly we tested grinding rates for each grit grade at different loads. We tested it by measuring of depletion of the capillary holder head with length contact gauge and TESA MODUL after given grinding time.

Table 1. Examples of grinding rates for speed $\mathrm{v}_{0}=3.5 \mathrm{~m} / \mathrm{s}$.

\begin{tabular}{|c|cccc|}
\hline \multirow{2}{*}{$v_{0}[\mathrm{~m} / \mathrm{s}]$} & \multicolumn{4}{|c|}{ Grinding rates $[\mathrm{nm} / \mathrm{s}]$} \\
\cline { 2 - 5 } 3,5 & \multicolumn{4}{|c}{ Load $\left[\mathrm{mN} / \mathrm{mm}^{2}\right]$} \\
\hline Grit grade & 14 & 40 & 100 & 220 \\
\cline { 2 - 5 } $3 / 2$ & 131 & 356 & \\
$1 / 0$ & 16 & 55 & 116 & 245 \\
\hline
\end{tabular}

Next we performed series of capillary face grinding and polishing according presented approach. We usually used two consecutive grinding steps, because removal rate of the last step was very low and it does not bring such expected effect to the capillary edge quality. 
Total grinding time took approximately 40-180 minutes in our case. After such grinding almost no defects were observed with 100-magnifying microscope in the capillary inner edge. Finally the capillary tip was finished with $\mathrm{Fe}_{2} \mathrm{O}_{3}$ polishing using polishing pad. This takes only 1-2 minutes, because longer machining time leads to sharp edge rounding.

We wanted to measure the quality and radius of machined capillary edge, but it showed to be a problem to find an appropriate instrument for it. This problem was limited by capillary inner diameter $0.32 \mathrm{~mm}$, the edge angle of $90^{\circ}$, the capillary length $35 \mathrm{~mm}$ and its fragility. Optical methods like confocal microscopes or optical profilometers have sufficient $3 \mathrm{D}$ resolution, but they are limited to measurement of surfaces with slope usually less than $30^{\circ}$ only. We tried to use an atomic force microscope (AFM) PSIA XE-100 equipped with high aspect ratio in contact-less mode. This measurement shows very good capillary face quality with roughness Ra $=0.6 \mathrm{~nm}, \mathrm{Rz}=2.7 \mathrm{~nm}$ on clear tip surface of dimensions $5 \times 5 \mu \mathrm{m}$. It enable us to measure the edge profile too as it is shown in the figure 6 .

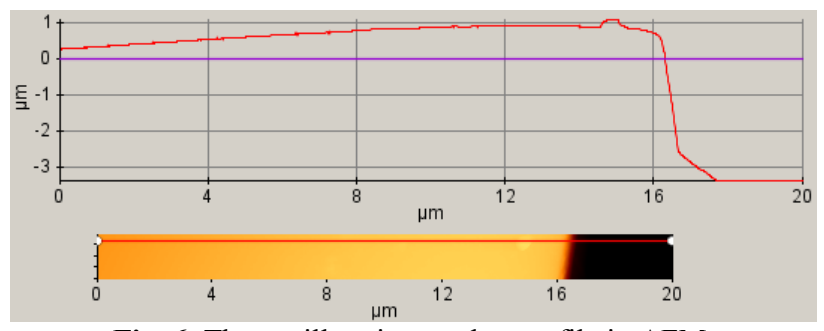

Fig. 6. The capillary inner edge profile in AFM.

We found out the edge radius changes along the edge but it was measured within the range 100-450 nm within observed area. AFM microscope enables us to measure only parts of the capillary edge, because of its work range limits $100 \mu \mathrm{m}$ in $\mathrm{X}, \mathrm{Y}$-axis, $\mathrm{Z}$-axis range $25 \mu \mathrm{m}$. The best way how to check the whole capillary edge or its details gave us a scanning electron microscope (SEM) only. It confirmed very good capillary edge quality, as it is shown in the figure 7.

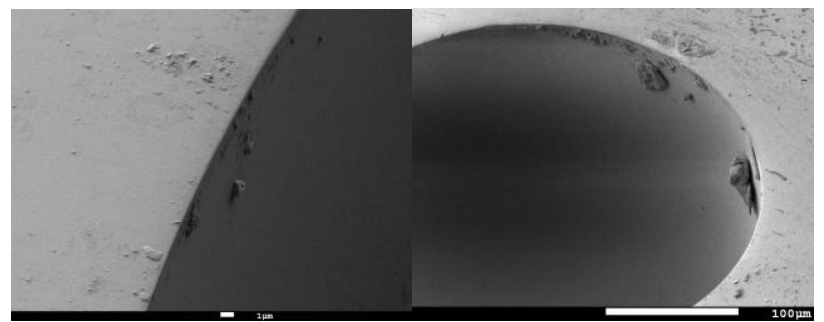

Fig. 7. Detail of the capillary inner edge in SEM.

\section{Conclusions}

Our results demonstrate possibility to achieve very sharp edges down to $100 \mathrm{~nm}$ radius on the brittle material as a fused silica capillary using classical optical grinding and polishing technology. Machine conditions, which allow achieving of sharp edges on brittle material, involve fine grinding with gradually or sequentially decreasing of infeed load during the grinding and finishing polishing.
This method, unfortunately, implies much longer working time then in the case of classical production grinding and still does not eliminate edge chipping on brittle material completely. We observed capillary edge chipping up to 3 $\mu \mathrm{m}$ radial dimensions within grinding period, which were finally smooth down by polishing process. Our experiments in liquid sample surface tension measurement using Ferguson method shows that such capillary chipping is acceptable for this measurement.

\section{Acknowledgement}

This work was supported by grant IAA200760905.

\section{References}

1. A. Ferguson, Proceedings of Physical Society 36 (1924) 37-43A

2. P. T. Hacker, Technical Note 2510, National Advisory Committee for Aeronautics, (1951) http://naca.larc.nasa.gov/reports/1951/naca-tn2510/naca-tn-2\%510.pdf.

3. J. Hošek, Proc. SPIE, Vol 6584, (2007)

4. T. Kurobe, Y. Yamada, H. Sugimori, Key Engineering Materials 238-239 (2003)

5. H. Nishida, K. Shimada, Y. Ido, Int. J. Appl. Elmag. Mech. 33 (2010)

6. J. Kang, H. Yamaguchi, Precision Engineering 36 (3) (2012)

7. T. Kanda, M. Mitsuhashi, T. Ueda, A. Tayohara, K. Yamamoto, Proc. SPIE 2567, (1995)

8. D. Hayes, Industrial Diamond Review 61 (589) (2002)

9. Y. A. Gharbia, J. Katupitiya, Machine Tools \& Manufacture 43 (2003)

10. M. G. Schinker, Precision Engineering 13 (3) (1991)

11. Z. Zhong, V. C. Venkatesh, Material Processing Technology 44 (1994)

12. S. Ch. Lin, M. L. Wu, Machine Tools \& Manufacture 42 (2002)

13. Y. A. Gharbia, J. Katupitiya, Machine Tools \& Manufacture 44 (2004)

14. H. Chai, B. R. Lawn, Acta Materiala 55 (2007)

15. K. Studenovský, J. Hošek, Fine Mechnics and Optics 52 (2007)

16. T. G. Bifano, T. A. Dow, R. O. Scattergood, Journal of Engineering for Industry 113 (1991)

17. B. K. A. Ngoi, P. S. Sreejith, The International Journal of Advanced Manufacturing Technology 16 (8) (2000) 